\title{
Lost in transition: Addressing the absence of quality surgical outcomes data in gender-affirming surgeries
}

\author{
Kinnon Ross MacKinnon, MSW, PhD'; Ethan Grober, MD, FRCSC ; Yonah Krakowsky, MD, FRCSC ${ }^{2}$
}

'Dalla Lana School of Public Health, University of Toronto, Toronto, ON, Canada; 2 Transition-Related Surgery Program, Women's College Hospital, Division of Urology, University of Toronto, Toronto, ON, Canada

Cite as: Can Urol Assoc J 2020;14(6):157-8. hitp://dx.doi.org/10.5489/cuaj.6610

\section{Key points:}

- Gender-affirming surgery (GAS) outcomes data are needed to provide surgeons and trans patients with the information necessary to make informed decisions.

- Robust GAS outcomes data are lacking and limit surgeons' abilities to draw conclusions on best surgical techniques.

- Two new GAS programs launched in Canadian academic hospitals offer a timely opportunity to address the absence of quality GAS data and to develop formal quality improvement initiatives.

Evidenced by previous calls to action in medical journals and in community, ${ }^{1,2}$ there is a growing sense of urgency surrounding the need to improve the health and well-being of transgender and gender diverse (trans) patients. One area of trans medicine currently undergoing transformation in Canada is gender-affirming surgeries (GAS), such as vaginoplasty and phalloplasty. Given the expanded availability of GAS in Canada, quality improvement efforts are required for surgeons to innovate surgical techniques and offer patients safer surgeries from a functional and cosmetic perspective. Some trans patients who are transitioning female-to-male, for instance, avoid phalloplasty due to risk of surgical complications. ${ }^{3}$ Standardized surgical outcomes data provides surgeons and patients with evidence-informed data, highlighting which procedures have higher and lower rates of complications, resulting in overall quality improvements to GAS, and therefore, less patient hesitancy. Yet robust GAS outcomes data are lacking. ${ }^{4}$ Canadian GAS outcomes data and quality improvement strategies are needed as a foundation to improve surgical techniques and to enhance informed medical decision-making for trans patients.

Given that two new GAS programs have recently opened in academic hospitals in Toronto and Vancouver, Canada is now well-positioned to lead GAS quality improvement and close the gap in surgical outcomes reporting. Canada's first public academic GAS clinic serving trans patients opened out of Women's College Hospital in Toronto in the summer of 2019. ${ }^{5}$ As of fall 2019, trans people in British Columbia can access GAS at the Vancouver General Hospital. ${ }^{6}$ Importantly, these new Canadian GAS clinics have been launched in hospitals that prioritize patient-centered care and advancing research. But there are lessons to be gleaned from the current state of the literature.

There are factors confounding GAS outcomes data quality with respect to surgical outcomes, quality of life, and psychosocial functioning in Canada and globally. One 2015 systematic review concludes that it is impossible to know "the 'best available' technique for vaginoplasty due to a lack of high-quality evidence and heterogeneity" of outcome measures. ${ }^{7}$ A 2019 systematic review of phalloplasty outcomes identifies that inconsistent outcomes reporting and a lack of comparative studies are significant limitations. ${ }^{8}$ Other areas of concern are that the defining principles of each surgical technique are not standardized, validated trans patient quality-of-life measures have yet to be developed, and the available data are divergent. Thus, reporting is unclear due to inconsistency with respect to surgical language and the absence of standardized validated GAS outcome tools. Ostensibly, patients and surgeons alike lack access to robust data reporting on the full spectrum of patient outcomes, including psychosocial and quality-of-life outcomes.

Several issues may have hindered the collection and availability of robust GAS outcomes data in Canada. First, inconsistent access routes, long waitlists, and a lack of surgeons specializing in GAS have forced many Canadian trans patients to seek surgeries out of their home cities and provinces. Some patients travel further still, to international 
countries, such as Thailand or Belgium. As such, patients return home following a short period of recovery and are lost to followup. Therefore, surgical outcomes data do not exist, as these data are simply not collected. Second, the private clinic model, characterizing most of the delivery of GAS in Canada until very recently, places the burden of empirically studying and reporting outcomes on non-academic and private surgeons, who are not compensated or trained for quality improvement work. Most private clinic surgeons responsible for managing clinics lack the institutional infrastructure to produce high-quality research. Finally, reflecting broader societal stigma and the desperate state of trans care broadly, it is not a far reach to postulate that the simple availability of GAS is seen as "better than nothing." In this way, some centers may be influenced by broader social norms, concluding that trans patients do not require the same surgical outcome analysis in order to proceed with surgery. Considering these three-fold factors that may affect the availability of robust GAS outcome data, better quality improvement practices, data collection tools, and reporting procedures are necessary.

New academic surgery programs offer solutions to quality improvement that could enhance the state of GAS. Canadian clinics performing GAS have launched electronic platforms that will enable the collection and storage of data. A provincial or national database of surgical outcomes in GAS would be the first of its kind. Furthermore, some Canadian hospitals participate in the American College of Surgeons' National Surgical Quality Improvement Program (NSQIP). The NSQIP is a "validated, risk-adjusted, outcomes-based program to measure and improve the quality of surgical care. ${ }^{\prime 9}$ One American study uses data obtained from the NSQIP to evaluate GAS safety profile. ${ }^{4}$ Canadian hospitals and private clinics offering GAS could participate in the NSQIP and may even consider a future cross-national comparative quality improvement study.

Another suggestion to balance the need to innovate surgical practices while protecting patient safety, is to establish surgical innovation committees under the direction of research ethics boards. ${ }^{10} \mathrm{~A}$ national Canadian surgical innovation committee established by Women's College Hospital and Vancouver General Hospital could work together in a rigorous scientific process to establish standardized GAS measurement tools. Developing consistent language to describe techniques, and measurement tools to capture GAS surgical outcomes and patient quality of life will improve GAS data quality, identified as a major limitation by previous systematic reviews. ${ }^{7,8}$

Currently, with the introduction of two new public GAS clinics, Canada is uniquely positioned to lead the call to action to improve the availability of rigorous GAS outcomes data. When GAS procedures are performed in Toronto and Vancouver - cities with large trans populations - patients are less likely to be lost to followup due to travel out of city, province, or country. But to address alarming gaps in the literature, it is imperative to commit to quality improvement, the scientific study of GAS outcomes using reliable and validated data collection tools, and the proper reporting these data. Trans patients need and deserve quality improvement efforts to make informed decisions that will impact their quality of life and psychosocial health outcomes. It is our social and ethical responsibility to collect and publish outcomes data. Moreover, surgeons require these data to advance GAS surgical techniques, which will ultimately enhance skills and benefit patients in turn. This opportunity must not be squandered.

Competing interests: Dr. Grober has been an advisory board member for Acerus, Apotex, Mylan, and Paladin; and holds investments in MHB Labs. Dr. Krakowsky has been an advisory board member for Acerus and Paladin; and a speakers' bureau member for Pfizer. Dr. Mackinnon reports no competing personal or financial interests related to this work.

\section{References}

1. Thomson RM, Katikireddi SV. Improving the health of trans people: The need for good data. Lancet Pub Health 2019;4:e369-70. https://doi.org/10.1016/S2468-2667(19)30129-X

2. Lam JSH, Abramovich A. Transgender-inclusive care. CMAJ 2019;191:E79. hitps://doi.org/10.1503/ cmaj. 180954

3. Irwig, MS. Clinical dilemmas in the management of transgender men. Curr Opin Endocrinol Diabetes Obes 2017;24:233-9. https://doi.org/10.1097/MED.0000000000000337

4. Tran BNN, Epstein S, Singal D, et al. Gender affirmation surgery: A synopsis using American College of Surgeons national surgery quality improvement program and national inpatient sample databases. Ann Plast Surg 2018;80:S229-35. https://doi.org/10.1097/SAP.0000000000001350

5. Lieberman C. Toronto home to first public hospital in Canada that offers transition-related surgery. Global News [internet]. June 24, 2019. Available at: https://globalnews.ca/news/5426898/toronto-hospitalgender-reassignment-surgery/. Accessed Nov. 25, 2019.

6. CBC News. B.C. to open gender lower-surgery clinic in Vancouver this fall. CBC [internet]. Aug. 2, 2019. Available at: hitrps://www.cbc.ca/news/canada/british-columbia/gender-lower-surgery-transgender-clinicvancouver-1.5234139. Accessed Nov. 25, 2019.

7. Horbach SER, Bouman MB, Smit JM, et al. Outcome of vaginoplasty in male-to-female transgenders: A systematic review of surgical techniques. J Sex Med 2015:12:1499-1512. https://doi.org/10.1111/ jsm. 12868

8. Rooker SA, Vyas KS, DiFilippo ES, et al. The rise of the neophallus: A systematic review of penile prosthetic outcomes and complications in gender-affirming surgery. I Sex Med 2019;16:661-72. https://doi.org/10.1016/i.jsxm.2019.03.009

9. Canadian Association of General Surgeons [internet]. Ottawa: American College of Surgeons' national surgical quality improvement program. Available at: https://cags-accg.ca/patient-care/nsqip/. Accessed Nov. 25, 2019.

10. Georgeson K. Surgical innovation and quality assurance: Can we have both? Semin Pediatr Surg 2015;24:112-4. https://doi.org/10.1053/i.sempedsurg.2015.02.007

Correspondence: Dr. Yonah Krakowsky, Transition-Related Surgery Program, Women's College Hospital, Division of Urology, University of Toronto, Toronto, ON, Canada; yonah.krakowsky@sinaihealthsystem.ca 